This is the author version of: Van den Bedem, N. P., Dockrell, J. E., Van Alphen, P. M., Kalicharan, S. V., \& Rieffe, C. (2018). Victimization, bullying, and emotional competence: Longitudinal associations in (pre) adolescents with and without Developmental Language Disorder. Journal of Speech, Language and Hearing Research 61, 2028-2044. doi: 10.1044/2018_JSLHR-L-17-0429.

\title{
Victimization, Bullying, and Emotional Competence: Longitudinal Associations in (pre)Adolescents with and without Developmental Language Disorder
}

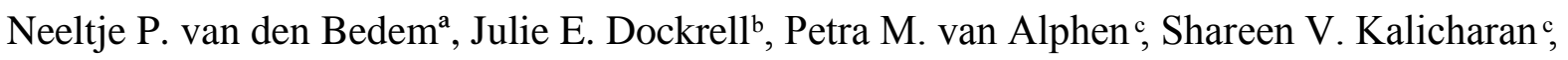
\& Carolien Rieffe ${ }^{a_{d}}$

\footnotetext{
a. Developmental Psychology, Leiden University, Wassenaarseweg 52, 2333AK Leiden, the Netherlands

b. Department of Psychology and Human Development, Institute of Education, UCL, 25 Woburn Square, UK

c. Royal Dutch Kentalis, Theerestraat 42, 5271 GD, Sint-Michielsgestel, the Netherlands.

d. NSDSK, Lutmastraat 167, 1073GX Amsterdam, the Netherlands
}

Correspondence to Neeltje van den Bedem: Department of Developmental Psychology, Leiden University, Wassenaarseweg 52, 2333AK Leiden, the Netherlands:

n.p.van.den.bedem@fsw.leidenuniv.nl. ORCID: 0000-0003-3865-685X

\section{Conflicts of interest: None}




\begin{abstract}
Purpose: Victimization is a common problem for many children, but is exacerbated for children with a developmental language disorder (DLD). However, the severity of communication problems does not explain their victimization rates. In children without DLD, difficulties with emotional competence are a risk factor for victimization, and also increase the risk of bullying. In this longitudinal study, we examined the extent to which the level and development of emotional competence (understanding of one's own emotions and levels of anger, sadness, and fear) contributed to the prediction of victimization and bullying in children with and without DLD, over and above the type and severity of communication problems of children with DLD.
\end{abstract}

Method: Clinically referred youngsters (8-15 years) with $(n=112 ; 48 \%$ girls $)$ and without DLD ( $n=233 ; 58 \%$ girls) completed self-reports three times over an 18 months period. Parents of children with DLD reported on their children's communication problems.

Results: Participants with DLD reported more victimization but comparable levels of bullying behavior compared to peers without DLD. Higher levels of sadness and fear were risk factors for more victimization in both groups. Better understanding of one's own emotions had a larger effect on less victimization in children with DLD, independent of their communication problems. Additionally, increased levels of anger and lower levels of understanding one's own emotions explained more bullying in both groups.

Conclusions: Outcomes indicate that secondary difficulties in emotional competence in children with DLD make these children more vulnerable to victimization, and warrant specific support and interventions.

Keywords: Emotion Understanding; Peer Rejection; Specific Language Impairment; Risk factors 


\section{Victimization, Bullying, and Emotional Competence: Longitudinal Associations in (pre)adolescents with and without Developmental Language Disorder}

Bullying is a common problem among children and adolescents, with long-lasting negative effects on the well-being for both victims and bullies (Ttofi, Farrington, Loesel, 2012; Ttofi, Farrington, Lösel, \& Loeber, 2011 for reviews). Bullying is behavior with the intention to harm another person. Often a group of children repeatedly turns against one child, resulting in a power imbalance (Olweus, 2013). Bullying can be either physical (e.g. hitting someone or taking their belongings), verbal (e.g. name calling), or social (e.g. gossiping about someone or ignoring someone) (Olweus, 1996).

Youngsters facing significant communication difficulties, as in a developmental language disorder ${ }^{1}$ (DLD), are particularly likely to be targets for bullies (Conti-Ramsden \& Botting, 2004; Redmond, 2011). Between 28 and 50\% of (pre)adolescents with DLD are victims of physical or verbal bullying, as compared to 12 to $22 \%$ of peers without DLD (Conti-Ramsden \& Botting, 2004; Knox \& Conti-Ramsden, 2003; 2007; Redmond, 2011). To date, social bullying has not been examined, but peers report more dislike of children with DLD (Andre’s-Roqueta, Adrian, Clemente, \& Villanueva, 2016). However, there are no clear associations between the social problems youngsters with DLD experience and the nature and severity of their language difficulties (Andre's-Roqueta et al., 2016; Charman, Ricketts, Dockrell, Lindsay, \& Palikara, 2015; Hart, Fujiki, Brinton, \& Hart, 2004). This suggests that the negative effect of language problems is mediated by other factors (Hart et al., 2004), which should be examined in order to help diminish the social problems of (pre)adolescents with DLD.

\footnotetext{
${ }^{1}$ DLD was formerly referred to as Specific Language Impairment, but for a discussion on the DSM-5 classification and terminology, see the work by Bishop et al., 2017.
} 
In youth without DLD, difficulties with emotional competence are a risk factor for victimization (Schwartz, Proctor, \& Chien, 2001; Spence, De Young, Toon, \& Bond, 2009). Emotional competence is an umbrella term for the ability to recognize one's own and others' emotions, to understand the causes and meanings of these emotions, and to regulate and express emotions in adaptive ways, in order to reach personal and social goals (Saarni, 1999). The development of emotional competence is highly dependent on communication within the social environment (Dunn, Brown, \& Beardsall, 1991; Saarni, 1999; Wiefferink \& Rieffe, 2012). Therefore, difficulties in emotional competence among children with DLD (Bakopoulou \& Dockrell, 2016; Fujiki, Spackman, Brinton, \& Hall, 2004) may form an extra risk factor for victimization, over and above their communication problems. However to date, it is unclear to what extent difficulties in emotional competence contribute to victimization in this particular group.

In addition, no research has been conducted on the bullying behavior of youngsters with DLD, although research in the general population shows that many youngsters who are being victimized also bully others (Cho, 2017; Olweus, 2013; Veenstra et al., 2005), especially when their emotional competence is low (e.g. Cook, Williams, Guerra, Kim, \& Sadek, 2010). The aim of this study is to examine the longitudinal relationship between emotional competence, victimization, and bullying in (pre)adolescents with and without DLD, over and above the type and severity of their DLD. Understanding which factors put youngsters with DLD at risk for negative peer interactions could inform future interventions.

\section{DLD and social development}

Most children develop language skills without difficulty. However, approximately two children in every classroom have significant difficulties acquiring and using language (Norbury et al., 2017; Tomblin et al., 1997). According to the DSM-5 (2013), children are diagnosed with a language disorder when their receptive or expressive language problems are 
not primarily caused by other disabilities, such as sensory disabilities or autism spectrum disorder, nor are their problems explained by intellectual disabilities (APA, 2013). Children with DLD may experience problems in both the content (semantics) and form of language (phonology, morphology, and syntax) (APA, 2013; Bishop, Snowling, Thompson, Greenhalgh, \& CATALISE consortium-2, 2017). In addition, children with DLD may also experience problems in language use in social interactions, that is pragmatics (Davies, Andrés-Roqueta, \& Norbury 2016; Norbury, Nash, Baird, \& Bishop, 2004). Some children have initial language delays that diminish over time (Stothard, Snowling, Bishop, Chipchase, \& Kaplan, 1998). However, children who enter primary school with DLD often continue to have problems (Snowling, Duff, Nash, \& Hulme, 2016).

The communication problems of youngsters with DLD negatively affect their academic achievements, but higher levels of emotional and social problems are also consistently reported in this group (Dockrell, Lindsay, \& Palikara, 2011; Snowling et al., 2016). For example, children with DLD show reduced friendship quality and more peer rejection (Botting \& Conti-Ramsden, 2008; Charman et al., 2015). For some children these social problems further increase during adolescence (St Clair, Pickles, Durkin, \& ContiRamsden, 2011). This is a worrying finding, because during adolescence young people are more sensitive to negative evaluations by peers, and this in turn is related to increasing levels of internalizing psychopathology in youth (Dahl \& Gunnar, 2009). Understanding and addressing the underlying mechanisms that contribute to the development of these social problems in youngsters with DLD could benefit the future mental health of these youngsters.

\section{Victimization in youngsters with DLD}

Dealing with small conflicts is an important part of normal social interaction. It allows children to master new skills, such as regulating and expressing negative emotions (Von Salisch \& Zeman, 2017). However, unequal power in peer relationships can make such 
conflicts problematic, such as in bullying. Bullies strive to dominate, and hope to grow in popularity at the expense of their victim. Therefore, they often choose victims who seem more vulnerable (Olthof, Goossens, Vermande, Aleva, \& Van der Meulen, 2011; Pellegrini \& Long, 2002), such as children with communication problems.

Social Adaptation Theory (Redmond \& Rice, 1998), which states that a child experiences social difficulties when the communicative demands of the environment exceed the communication abilities of the child, may explain the higher levels of victimization of youngsters with DLD. In reaction to a social environment that overwhelms their communication ability, a child with DLD may withdraw or become passive in social interactions, or show externalizing behavior, which in turn results in fewer or shorter social interactions, and thus less practice of their social and language capacities.

There is indeed some evidence that the severity and type of communication problems in children with DLD are associated with victimization or peer problems in general, although results are mixed. In five-year-olds, peer problems were found to be related to poorer semantic and syntactic language abilities (Van Daal, Verhoeven, \& Van Balkom, 2007). In a longitudinal study, more expressive language problems at the age of eight predicted higher levels of victimization at the age of 11 (Conti-Ramsden \& Botting, 2004). In the same study, problems with pragmatics at age 11 were unrelated to self-reported victimization, but were negatively related to peer competence, as rated by teachers. This is consistent with the finding that pragmatic problems in youngsters with DLD at the age of 11 contributed to the prediction of teacher rated peer problems at age 16 (St. Clair et al., 2016). Conversely, children with better syntactic comprehension reported more victimization in one study (Redmond, 2011), whereas another study found no relation between receptive language problems and peer problems as rated by teachers (Charman et al., 2015). Overall, the severity and type of DLD only explains a small part of the variance in reported victimization. This suggests that there is 
not a direct link between language problems and social problems in youngsters with DLD, but that this relation is mediated by other factors (Hart et al., 2004).

\section{Victimization and emotional competence}

A focus on communication problems alone may limit our understanding of the development of victimization in youngsters with DLD. Research with children without DLD shows that negative peer interactions are more common in children with less emotional competence. Victims have been described as children who experience less understanding of their own emotions, and exhibit higher levels of fear, sadness, and anger (Cook et al., 2010; Camodeca \& Goosens, 2005). High emotionality can result from victimization, but emotionality can also trigger bullying, because bullies often target children who are more easily dominated or provoked (Schwartz et al., 2001; Spence et al., 2009).

The high incidence of victimization of youngsters with DLD might be also explained by their difficulties in their emotional competence, which in turn are affected by their communication problems. Emotions play a key role communicating in daily life, signaling what is important (Frijda, 1986). Yet, for children to use this information they must be aware of their own emotions, and recognize emotions in others (Rieffe, Oosterveld, Miers, Meerum Terwogt, \& Ly, 2008). They also need to understand what caused these emotions and what the goal is of a person given their emotion, e.g. an angry person wants to change something in a situation, whereas a sad person tries to come to terms with a loss (Frijda, 1986; Rieffe et al., 2008). Understanding the cause of an emotion is important to deal effectively with an emotion-evoking situation (Eisenberg et al., 1993; Gross, 2015). Finally, children must learn how to express their own emotions in line with the social rules of the environment (Saarni, 1999; Schaffer, 2005). This requires good emotion regulation, i.e. the ability to adapt the level of emotional experience or the expression of the emotion to the social environment (Gross, 2015). 
Emotional competence develops through the process of emotion socialization, where children learn through social interaction to recognize, understand, regulate, and express emotions according to the social rules of their environment (Saarni, 1999; Schaffer, 2005). Through language, children have access to their social world and the opportunity for social learning (Saarni, 1999). Social interactions help children acquire the linguistic skills for communicating about emotions, because parents label the feelings of children and help them express their own feelings (Dunn, Brown, \& Beardsall, 1991; Saarni, 1999). Indeed, higher quality emotion talk between parents and children is related to more emotional competence (Dunn et al., 1991; Denham \& Auerbach, 1995). Furthermore, social interactions provide children with learning opportunities for understanding what caused their emotions, and becoming adept at regulating and expressing their emotions constructively in social interactions (Dunn et al., 1991; Saarni, 1999; Wiefferink \& Rieffe, 2012). Peer interactions also form an important context for social learning, as shown by research on free play situations (Veiga et al., 2017). Emotional competence, in turn, is essential for developing meaningful social relationships (Eisenberg et al., 1993; Longobardi, Spataro, Frigerio, \& Rescorla, 2016). Through these social relationships, children further develop emotional competence, especially when relationships become more intense and complex, as in the early teenage years (Von Salisch \& Zeman, 2017).

When children experience severe communication problems, they have less opportunity for social learning (Botting \& Conti-Ramsden, 2008; Rieffe, Dirks, Van Vlerken, \& Veiga, 2016). Conversations are less easily processed or can be misunderstood, discussions are more difficult to participate in and social or play situations are less easily joined. Opportunities to develop emotional competence can thus be hindered. There is a growing body of research indicating that children with DLD experience problems with emotional competence. The majority of research has focused on the recognition or understanding of others' emotions. 
While toddlers with DLD are not reported to have problems matching drawings of basic emotions, labelling others' emotions appears to be more challenging (Rieffe \& Wiefferink, 2017). Pupils with DLD in elementary school are reported to have difficulty recognizing emotions from photographs (Taylor, Maybery, Grayndler, \& Whitehouse, 2015) and adolescents with DLD have more problems in the recognition of emotions reflected in the eye region in photos (Botting \& Conti-Ramsden, 2008). Additionally, children with DLD are reported to have difficulty recognizing emotions from the intonation of neutral sentences (Creusere, Alt, \& Plante, 2004; Fujiki, Spackman, Brinton, \& Illig, 2008; Taylor et al., 2015), from discourse (Ford \& Milosky, 2008), and inferring emotions from stories (Bakopoulou \& Dockrell, 2016; Ford \& Milosky, 2003; Spackman et al., 2006).

Considerably less research has focused on the understanding of one's own emotions. As may be expected, children with DLD have a smaller emotion lexicon, and experience more difficulty talking about emotions (Bakopoulou \& Dockrell, 2016; Rieffe \& Wiefferink, 2017; Spackman et al., 2006), but whether children and adolescents with DLD have difficulty understanding the causes of their own emotions is yet unclear. Emotion regulation has been found to be less adaptive in elementary school children with DLD. Children with DLD are reported to experience more difficulty expressing their own emotions and reacting adaptively to the emotions of others by their teachers (Fujiki et al., 2004). In hypothetical scenarios where someone's feelings might be hurt by the expression of emotions, children with DLD reported less need to regulate their emotions than peers without DLD. However, in real life situations, these children hid their emotions to the same extent as their peers without DLD (Brinton, Fujiki, Hurst, Jones, \& Spackman, 2015).

There is increasing evidence that early problems with social-emotional skills outweigh the direct effects of communication problems on the social relations of youngsters with DLD (Bakopoulou \& Dockrell, 2016; Botting \& Conti-Ramsden, 2008; Hart et al., 2004; Lindsay 
\& Dockrell, 2012; Mok, Pickels, Durkin, \& Conti-Ramsden, 2014). Therefore, it is possible that the high incidence of victimization in (pre)adolescents with DLD can be explained by difficulties with emotional competence, over and above the severity of their communication problems.

\section{Bullying and emotional competence}

Victims are not the only ones with lower emotional competence. Youngsters with a greater tendency to bully have more problems understanding other people's emotions, have problems regulating their own emotions, and usually show elevated levels of anger (Camodeca \& Goosens, 2005; Cook et al. 2010). Additionally, many bullies are also being victimized, and victimization in turn makes children more prone to increased levels of bullying (Cho, 2017; Olweus, 2013; Veenstra et al., 2005). These so-called "bully-victims" are particularly likely to demonstrate problems with emotion regulation (e.g. Cook et al., 2010; Schwartz et al., 2001).

Studies on the development of bullying from childhood to adolescence in children without DLD show an overall decline in bullying. However, bullying tends to peak as children transition from primary to secondary education (Pellegrini \& Long, 2002). In addition, there seems to be a wide variety of individual trajectories in the level of bullying (Underwood, Beron, \& Rosen, 2009). Therefore, it is important to consider individual differences, in order to understand how bullying behavior develops. To date neither the etiology of bullying, nor the role of emotional competence in bullying, has been examined in children or adolescents with DLD.

\section{Present study}

Victimization is more prevalent in (pre)adolescents with DLD, but it is unclear which factors put these youngsters more at risk than peers without DLD. In this study, we examined the longitudinal relations between victimization and bullying, with two indices of emotional 
competence (understanding of one's own emotions and level of negative emotions) in (pre)adolescents with and without DLD, over and above communication problems of the children with DLD. A sample of Dutch youngsters between the ages of 8 and 15 years old reported on their victimization, bullying, and emotional competence on three occasions over an 18 month period. We chose this age range because during puberty, children become increasingly sensitive to the opinions of their peers, which makes bullying especially problematic for their mental health (Dahl \& Gunnar, 2009). During this period, bullying takes on more covert, social forms, which are less detectable by parents and teachers (Crick, Casas, \& Nelson, 2002). Therefore, we used a self-report measure that included social bullying.

First, the level and changes over time of bullying, victimization, and emotional competence in (pre)adolescents with and without DLD were compared. Based on previous research, we expected more victimization and lower emotional competence in youngsters with DLD, compared to those without DLD (Bakopoulou \& Dockrell, 2016; Botting \& ContiRamsden, 2008; Brinton et al., 2015; Conti-Ramsden \& Botting, 2004; Fujiki et al., 2004; Knox \& Conti-Ramsden, 2003; Redmond, 2011). Because children who are being victimized often bully other children as well (Cho, 2017; Olweus, 2013; Veenstra et al., 2005), higher levels of bullying behavior in youngsters with DLD might also be expected. In addition, we expected decreases in victimization and bullying in adolescents without DLD (Pellegrini \& Long, 2002; Underwood et al., 2009). In contrast, increasing levels of victimization might be expected in youngsters with DLD, because more social problems have been reported by parents of this particular group (St. Clair et al., 2011).

Second, we examined the extent to which the level and changes in emotional competence contributed to the prediction of victimization and bullying, in youngsters with and without DLD. Due to the frequently noted problems with emotional competence, (pre)adolescents with DLD may be provoked more easily, and in turn become more 
vulnerable to victimization, as well as to bullying. Therefore, we expected greater negative relations between indices for emotional competence, with both victimization and bullying in youngsters with DLD, compared to peers without DLD (Camodeca \& Goosens, 2005; Cook et al. 2010; Knox \& Conti-Ramsden, 2007; Schwartz et al., 2001; Spence et al., 2009).

Third, we examined whether the type and severity of communication problems of youngsters with DLD could explain within group differences in the level of bullying or victimization. We expected higher levels of victimization in youngsters with DLD with more communication problems (Conti-Ramsden \& Botting, 2004; St. Clair et al., 2016).

Finally, we examined whether emotional competence contributed to the prediction of victimization and bullying in children with DLD, when we controlled for the type and severity of their communication problems. We expected that indices for emotional competence would contribute to the prediction of victimization over and above the severity of their communication problems (Hart et al., 2004; Knox \& Conti-Ramsden, 2007; Lindsay \& Dockrell, 2012).

\section{Methods}

\section{Design}

Youngsters with and without a clinical diagnosis of DLD were followed over a period of 18 months. There were three measurements, with 9 months between each wave. At each measurement, youngsters reported on their own victimization, bullying, and two indices for emotional competence: understanding of one's own emotions, and level of negative emotions. Parents of children with DLD reported on the type and severity of communication problems of their child at Time 1 . In addition, performance IQ (PIQ) information was obtained from school files for children with DLD, or it was tested at the second measurement.

\section{Participants}


A total of 326 Dutch (pre)adolescents between the ages of 8 and 15 years old participated in this study. Of these, 112 were previously diagnosed with DLD (Table 1). Participants with DLD were recruited through primary and secondary schools for children with DLD, and through specialised organisations that support children with DLD in regular education. Participants were included when they had a diagnosis of DLD according to DSM-4 criteria, and no other disorders such as autism spectrum disorder or a hearing impairment.

In line with government protocols, diagnoses are provided by an audiological centre where qualified professionals examine the language abilities, PIQ, and hearing of children using standardized tests. Children receive a diagnosis of DLD when their receptive or expressive language problems fall 1.5 SD below the mean in two out of four language areas, which are auditory working memory, speech production, language form, and language content. These language problems should not be resolved after six months of speech and language therapy. Typically, the Dutch version of the Clinical Evaluation of Language Fundamentals (CELF) is used to test the language abilities of children (Kort, Schittekatte, \& Compaan, 2008). Diagnosis are renewed every five years and children with a diagnosis of DLD are eligible for governmental support.

Eleven children with DLD also had a diagnosis of $\mathrm{ADD}$ or $\mathrm{ADHD}$. $\mathrm{AD}(\mathrm{H}) \mathrm{D}$ is frequently diagnosed in children with DLD (e.g. McGrath et al., 2008). This could be due to high co-morbidity of both disorders, but it could also be caused by difficulties distinguishing initial language problems from secondary behavioral problems (Im-Bolter \& Cohen, 2007). Therefore, children with an additional diagnosis of $\mathrm{AD}(\mathrm{H}) \mathrm{D}$ were not excluded from the $\mathrm{DLD}$ group. All analyses were conducted with and without these children, which did not change the results.

The majority of the children with DLD $(n=80,71.4 \%)$ attended a specialised school for children with DLD, where they received specialised education in smaller groups with 
extra attention for their language development, and speech and language therapy at school. The other children with DLD attended mainstream schools where they received extra help from specialized organizations. Children typically have a counsellor who regularly visits the school to inform teachers of the communication needs of the child, and to help the child with schoolwork, communication with others, and related issues. In addition, children with DLD often receive speech and language therapy outside of school.

The youngsters without DLD were recruited through mainstream schools and were included when they had no diagnoses (including ADHD), no language problems as measured with two sub-tests of the CELF (Semantic Relations and Text Understanding), and PIQ within the normal range. The present study is part of a larger research project on the social and emotional development of children and adolescents who face less access to the social environment while growing up because of deafness, autism spectrum disorder, or DLD. Cross-sectional data of a subsample of the group without DLD has been reported before (Kouwenberg, Rieffe, \& Theunissen, 2011; Rieffe et al., 2011).

The groups with and without DLD, were comparable in terms of the mean age and gender distribution (Age: $t(165.88)=.84, p=.401, d=.10$; Gender: $X^{2}(1)=2.07, p=.155$ ) (Table 1). Both groups consisted predominantly of youngsters with one or two Dutch parents (without DLD: 91.4\%, with DLD: 92.5\%). The parents of other participants came from Turkey, Morocco, Surinam, and other unspecified countries. Participants with DLD had lower PIQ than those without $\operatorname{DLD}(t(264,99)=7.56, p<.001, d=.93)$, and lived in less wealthy neighborhoods than youngsters without DLD, as indicated by their postal code $(t(316)=3.81$, $p<.001, d=.45$ ). This has been found in many studies of children with DLD (e.g. Norbury et al., 2017), but this was also due to above average Neighborhood SES of the group of participants without DLD. The analyses were controlled for PIQ and Neighborhood SES. 
All parents and the youngsters with DLD above 12 years of age gave written informed consent. The study was approved by the ethical committee of Psychology at Leiden University.

[Table 1 about here]

\section{Materials}

Bullying and Victimization were measured using the Dutch version of the revised Bully/Victim Inventory (Kouwenberg et al., 2011; Olweus, 1996). This self-report questionnaire was found to be reliable in previous research with Cronbach's alpha's ranging between .80 and .90 in different samples, and good convergent validity with peer nomination measures (for a review see Olweus, 2013). Also in deaf youngsters, good reliability was found for the victimization scale $(\alpha=.82$; Kouwenberg, et al., 2011). Children were first introduced to a definition of bullying, including several examples. Next, they were presented with nine questions describing different forms of bullying, including physical bullying (e.g. taking or breaking someone's belongings), verbal bullying (e.g. name-calling), and social exclusion (e.g. acting like you cannot see or hear someone). Children could answer on a three-point Likert scale if they never (1), sometimes (2), or often (3) bullied others.

To measure victimization, the same questions were presented to the youngsters, but this time they were asked if they had been the victim of these different bullying behaviors. Because children with disabilities more often are ignored or neglected by their peers, an extra item was added to the questionnaire, asking if they were invited to birthday parties (reversed scored) (Kouwenberg et al., 2011). The Cronbach's alpha for the bullying and victimization questionnaires was found to be acceptable for the group without DLD $(\alpha>.70)$ and good for children with DLD $(\alpha>.80$; Table 2$)$.

Understanding one's own Emotions was measured using a scale from the revised Emotion Awareness Questionnaire for children (Rieffe et al., 2008), a questionnaire that has 
been cross-validated in different languages and countries (Lahaye et al., 2011). The "differentiating emotions" scale asked children to rate how well they understood the causes of their own basic emotions (anger, sadness, and fear), and whether they could differentiate between their own emotions, as opposed to having a vague general negative feeling about a situation (7 items; e.g., I often do not know why I am mad; I find it difficult to know if I feel mad, sad, or something else). Children indicated whether the statements were not true (3), sometimes true (2), or often true (1). A high score represented good understanding of one's own emotions. The scale showed good convergent validity, indicated by a positive correlation with emotional intelligence $(r=.52 * *)$, and by the expected negative correlations with depression and social anxiety ( $r=-.36^{* *}, r=-.43^{* *}$ respectively) (Rieffe et al., 2008). Acceptable reliability has been reported in different samples $(\alpha>.67)$, including in children with communication difficulties (Lahaye et al., 2011; Rieffe et al., 2008; Rieffe et al., 2011). In our study, reliability was also found to be acceptable for both groups $(\alpha>.70$; Table 2$)$.

The level of negative emotions was measured with the Mood questionnaire (Rieffe, Meerum Terwogt, \& Bosch, 2004). Children were asked how they felt in the past four weeks, and were presented with a list of emotions, including different words for anger (4 items; e.g. mad, angry, furious), sadness (4 items), fear (5 items), and happiness (5 items). Children could indicate whether they had felt the emotion (almost) never (1), sometimes (2) or often (3). The simple language makes this questionnaire well suited for children with communication difficulties. The internal consistency of the scales have been established in earlier studies $(\alpha>$.70) (Rieffe et al., 2004). For this study, only the three negative emotion scales were used. Reliability for all scales was acceptable to good for both groups $(\alpha>.78$; Table 2).

[Table 2 about here] 
Performance IQ data were unavailable from school files for eight $(7.1 \%)$ youngsters with DLD and all youngsters without DLD. Therefore, an indication of PIQ was obtained through two subscales of the Wechsler Intelligence Scale for Children, Third Edition (Block Design and Picture Arrangement; Kort et al., 2005). These subtests provide a good estimation of the PIQ of children tested with a complete version of the WISC (Theunissen et al., 2011). Ten children with DLD scored between 70 and 78 and four children without DLD had a PIQ of 78. Because this score falls within the $95 \%$ confidence interval of a PIQ of 85 , these children were not excluded. All analyses were repeated without the children with low PIQ scores, and this did not change the results. Data were missing for five (4.5\%) youngsters with DLD and 31(14.5\%) youngsters without DLD due to attrition, or because parents did not give their consent to obtain information about PIQ (Table 1).

Communication problems of youngsters with DLD were assessed with the Dutch version of Bishops' Childs Communication Checklist (CCC-2-NL), which measures communication problems in children between 5 and 15 years old (Norbury et al., 2004; Geurts et al., 2009). The CCC-2-NL consists of 56 questions about speech production, syntax, semantics, coherence in discourse, and four pragmatic scales: initiation of conversations, nonverbal communication, use of context, and stereotypical language use. The two scales which were developed to screen for an autism spectrum disorder were not administered in this study. Parents were asked to indicate whether a certain communication behavior occurred three or more times a day (3), once or twice a day (2), once a week (1), or less than once a week (0). Sum scores were calculated for all scales. Higher scores represented more communication problems. Data from the CCC-2-NL were missing for $17(15.2 \%)$ youngsters with DLD due to non-response of parents, or due to unreliable answers in the positively stated questions. All scales had acceptable to good reliability (Table 2).

\section{Common measure variance}


Because we use different self-reports, common measure variance may influence our results. However, it has been shown that this effect is especially salient when different measures are highly related both conceptually and in the way questions are stated (Podsakoff, Mackenzie, Lee, \& Podsakoff, 2003). In our study, the emotional competence measures were used to predict the social problems. These topics and the way questions were stated in the different questionnaires were not very similar. Therefore, the common measure variance may not have such a strong effect on the relations between these measures. However, the bullying and victimization questions do resemble each other strongly and the two concepts are closely related. In order to diminish this effect, the questionnaires about bullying and victimization were not presented right after each other, as recommended by Podsakoff and colleagues (2003).

\section{Procedure}

Participants were tested individually at school or at home by a trained test leader following a detailed protocol. The group of test leaders consisted of four $\mathrm{PhD}$ students, three research assistants with a master degree in child psychology and 24 master students in developmental psychology. It was emphasized that all answers would be anonymous and that there were no right or wrong answers. Participants filled out self-report questionnaires on a laptop or tablet. For children with DLD, all questions were read aloud by the test leader. Participants were able to ask for explanations at any point if they did not understand a question. Parents of children with DLD filled out the CCC-2 on paper or through the internet.

\section{Statistical Analyses}

The current study uses longitudinal data at three points in time. Multiple observations in participants causes dependency within the data, which violates the assumption of linear regression analyses. Therefore, we used multi-level regression models, which can correct for 
the dependency in the data (Singer \& Willett, 2003; Snijder \& Bosker, 2012). The analyses were run using the lme4 package in R 3.3.2 (The R Foundation, 2016).

As in most longitudinal studies, we had to deal with attrition. There were eight (7\%) youngsters with DLD and $31(14.5 \%)$ without DLD who did not participate at Time 2, and another $6(5.4 \%)$ youngsters with and $27(12.6 \%)$ without DLD who could not be retraced, or did not want to participate anymore at Time 3. Information was available at all three time points for $98(88 \%)$ youngsters with and $156(73 \%)$ without DLD. We compared participants who participated three times with participants who did not participate throughout the whole study. No differences were found within the DLD group, but in the group without DLD, youngsters who did not participate three times lived in less wealthy neighborhoods $(t$ (56.79) $=3.59, p=.001)$. Multi-level data analyses are appropriate for dealing with missing data, because it uses all available data for every participant (Van Buuren, 2012). Therefore, children with missing data on one or two time points were included in the study. Maximum Likelihood estimation was used (Van Buuren, 2012).

We used a formal model testing procedure where we compared increasingly more complex models with each other. The best fitting models explained the most variance within the data with the fewest predictor variables. This was indicated by Akaike's Information Criterion (AIC). The AIC compares the model fit to the data, but penalizes models with more predictor variables. When the model explains sufficiently more variance when a variable is added, the AIC becomes lower (Singer \& Willett, 2003). Models were only reported when the reduction in AIC was significantly lower with $p<.05$. We calculated the $95 \%$ Confidence Intervals (CI) of all predictor variables within a model. When the CI does not contain 0 , the variable makes a significant contribution to the prediction of the dependent variable.

The first aim of the study was to compare the level and changes across time of Bullying, Victimization, and indices for Emotional Competence between (pre)adolescents, 
with and without DLD. We fitted basic mean models as a baseline. Then, we examined whether the age in years (centered around the mean) of the children was related to the level of bullying, victimization, and emotional competence, while controlling for the Gender and Neighborhood SES of the children. Next, in order to examine differences between youngsters with and without DLD, Diagnosis (without DLD = 0, with DLD =1) was added to the model. In addition, we examined whether the changes across time in the level of Victimization, Bullying, and the indices for Emotional Competence differed in youngsters with and without DLD by adding the interaction of Age $\mathrm{x}$ Diagnosis.

All analyses were examined for differences between children with DLD from special education and children in regular schools, but no differences occurred. Therefore, children with DLD from mainstream and special education were collapsed over group. In addition, all analyses were repeated with the addition of random slopes, but these did not provide better model fits and were excluded.

The second aim was to examine the predictive value of Emotional Competence (Understanding one's own Emotions and level of Negative Emotions) on the development of Victimization and Bullying. Therefore, the predictor variables were decomposed to form a Mean score (mean of Time 1, Time 2, and Time 3 for every participant) and time-varying Change score (the score on every time point minus the mean score for every participant). The mean score was added to the model in order to examine whether differences in the level of a predictor variable explained differences between participants in the level of Victimization and Bullying. The Change scores were added to examine whether individual changes over time in the predictor variable predicted increasing or decreasing levels of Victimization and Bullying (Singer \& Willett, 2003). First, a model was fitted with Age, Neighborhood SES, Gender, Group, and Bullying or Victimization (Mean and Change), to account for the high interrelation between Victimization and Bullying (Olweus, 2013). Second, the Mean and 
Change score of Understanding of one's own Emotions were added to the model. Finally, the interaction terms of Group x Understanding of one's own Emotions (Mean and Change) were added in order to compare the predictive value of Understanding one's own Emotions for children with and without DLD. A parallel analysis was run with the Mean and Change scores of the three Negative Emotions (Anger, Fear, and Sadness).

The third aim was to examine whether the Communication problems of children with DLD at Time 1 contributed to the prediction of the development of Victimization and Bullying. The CCC-2 was not filled out for 17 (15\%) children with DLD, but we did not find any differences between children whose parents did and did not fill out the CCC-2. Therefore, we were fairly confident that the missing data were at random. A multilevel model with Age, Gender, and Neighborhood SES was compared with a model with the addition of one of the CCC-2 scales.

The final aim was to examine if the indices of Emotional Competence could explain the level of Victimization and Bullying over and above the severity of Communication Problems of children with DLD. Therefore, a multi-level model with the indices of Emotional Competence was compared to models with the addition of one of the CCC-2 scales.

\section{Results}

\section{Preliminary analyses}

Because children reported on their own emotional and social problems, we tested whether the common method bias influenced our results. We performed an exploratory factor analysis with the items of the victimization, bullying, and emotional competence questionnaires. The number of allowed factors was constrained to one. The analysis showed that the first factor only accounted for $20.4 \%$ of the variance, which indicates that common method bias was not significantly influencing the results (Podsakoff et al., 2003). 


\section{Group differences}

Our first aim was to compare the level and development of Victimization, Bullying, and the indices for Emotional Competence of youngsters with and without DLD. Table 3 presents the models that showed the best model fit (see Appendix 1 for an overview of all models). In Figure 1 all longitudinal data, as well as the predicted values based on the age and diagnosis of the participants, are presented. Youngsters with DLD reported higher levels of Victimization, Sadness, and Fear. No group differences were found for Bullying, Understanding of one's own Emotions, and Anger. Victimization and Bullying showed a decrease in older children in both groups alike, whereas Understanding of one's own Emotions increased in adolescents. The level of Anger, Sadness, and Fear did not differ across time in the group without DLD, whereas in youngsters with DLD, the three negative emotions decreased in older children. The addition of PIQ did not alter the results, and is therefore not reported.

[Table 3 about here]

[Figure 1 about here]

\section{The predictive power of Emotional Competence on Victimization and Bullying}

Our second aim was to examine the extent to which indices for emotional competence could explain the development of Bullying and Victimization in (pre)adolescents with and without DLD (Table 4; and see Appendix 2 for an overview of all models). First, we controlled for the interrelation between Bullying and Victimization. Youngsters who reported more Bullying (Mean), as well as an increase in Bullying over the 18 months of the study (Change), reported higher levels of Victimization. In addition, the Mean level of Understanding of one's own Emotions explained lower levels of Victimization in both groups. However, this relation was moderated by Diagnosis, indicating that Understanding of one's 
own Emotions had a greater effect on less Victimization in (pre)adolescents with DLD than in peers without DLD (Figure 2).

[Table 4 about here]

[Figure 2 about here]

Bullying was also explained by higher levels of Victimization and an increase in Victimization over time. In addition, youngsters with more and increasing levels of Understanding of one's own Emotions were less likely to Bully their peers in both groups.

Next, we examined the predictive power of Anger, Sadness, and Fear on the level and development of Victimization and Bullying. As Table 5 shows, higher levels of Sadness and Fear, as well as an increase in Sadness and Fear over time, explained higher levels of Victimization in both groups. Anger did not contribute to the model. Conversely, Bullying was only explained by higher and increasing levels of Anger. The strengths of these longitudinal associations were comparable in both groups.

[Table 5 about here]

\section{The predictive power of Communication Problems on Victimization and} Bullying

Our third aim was to examine whether higher levels of Victimization in (pre)adolescents with DLD could be explained by the type and severity of their Communication Problems. The separate scales of the CCC- 2 were added one by one to the model, including Age, Gender, Neighborhood SES, and Bullying (Mean and Change). The results showed that Speech, Semantic, Coherence, and Pragmatic problems at Time 1 were associated with more Victimization in youngsters with DLD. Syntax problems did not contribute to Victimization. Pragmatic problems provided the best model fit (Table 6). Moreover, when more than one scale was added to the model, only the Pragmatic Problems remained significant. 
Bullying behavior of youngsters with DLD was also associated with higher levels of Pragmatic, Semantic, and Coherence problems. However, when the level of Victimization was accounted for in the model, the communication problems did not explain any additional variance.

[Table 6 about here]

Our final aim was to examine whether indices for Emotional competence would predict Victimization over and above the type and severity of Communication Problems of children with DLD. Table 6 shows that less Understanding of one's own Emotions, and more Sadness and Fear, contributed to higher levels of Victimization, also after controlling for Pragmatic language problems of youngsters with DLD. Speech, Syntax, Semantic, and Coherence problems did not contribute to Victimization when Emotional Competence was controlled for.

\section{Discussion}

Being involved in bullying, either as aggressor, victim, or both, can have lifelong negative consequences (Ttofi et al., 2011; 2012). Some (pre)adolescents are more at risk for these kinds of peer problems, including youngsters with DLD (Conti-Ramsden \& Botting, 2004; Redmond, 2011). The level of communication difficulties might cause more peer problems as youngsters get older (St. Clair et al., 2011). However, difficulties with emotional competence may also underlie and reinforce peer problems. The current study examined the role of emotional competence in the victimization and bullying of children with DLD.

The results confirm previous studies that (pre)adolescents with DLD reported higher levels of victimization than their peers without DLD (Conti-Ramsden \& Botting, 2004; Knox \& Conti-Ramsden, 2003; 2007; Redmond, 2011). Our study is the first to examine the development of victimization over time in this particular group. Victimization decreased over time in participants with DLD, just as in youngsters without DLD. Yet victimization increased 
over time in youngsters who also bullied others more often. Participants with DLD reported more sadness and fear than peers without DLD and these levels decreased in older children. Higher and increasing levels of sadness and fear, but not anger, contributed to the prediction of more victimization in youngsters with and without DLD (Camodeca \& Goosens, 2005; Schwartz et al., 2001; Spence et al., 2009). The level of understanding of their own basic emotions did not differ between the groups, but higher levels of understanding of one's own emotions contributed more strongly to less victimization in youngsters with DLD, over and above their communication levels. In fact, understanding of one's own emotions in youngsters with DLD had a greater effect on victimization than their communication levels. Gender, performance IQ, and our index for socio-economic status did not alter these outcomes.

To the best of our knowledge, this study is also the first to examine bullying in children with DLD. The outcomes showed that the groups with and without DLD did not differ in how often they bullied others on a general measure including different forms of physical, verbal, and social bullying (Olweus, 1996). Boys in both groups reported higher levels of bullying behaviors than girls. Yet neither group nor gender interacted with the outcomes of the models that examined the occurrence of bullying. It appeared that higher and increasing levels of victimization contributed to the prediction of more bullying. As for emotional competence, higher and increasing levels of anger, and lower and decreasing levels of understanding of one's own emotions, contributed to the prediction of more bullying over and above victimization. These outcomes did not change when communication levels of children with DLD were controlled for. Gender, performance IQ, and socio-economic status did not alter these outcomes.

Consistent with studies in community samples (Cho, 2017); our data supported a bidirectional causal relationship between bullying and victimization in youngsters with DLD. It has been argued that victims of bullying start bullying others in order to defend themselves. In 
turn, especially these 'reactive' bullies, who react emotionally, are more vulnerable to victimization (Cook et al., 2010). In addition, victims might become habituated to this kind of violence and think that this is normal behavior to 'survive' socially (Bushman \& Anderson, 2009). Because (pre)adolescents with DLD are victimized more often, this makes them vulnerable to becoming bully-victims. Interventions can prevent this from escalating.

As predicted, better communication levels contributed to the development of less victimization in children with DLD. However as expected, these relations were less important than the emotional competence of these youngsters in the longitudinal models that were tested in this study (Hart et al., 2004; Knox \& Conti-Ramsden, 2007; Lindsay \& Dockrell, 2012). Increased levels of fear and sadness, both emotions that reflect the tendency to withdraw from the situation causing negative feelings (Frijda, 1986), contributed to the development of more victimization in youngsters with and without DLD. It is possible that individuals who show their fear or sadness validate the bully's sense of power (Olthof et al., 2011). Yet increasing levels of anger, an emotion that aims to confront the other person with perceived injustice (Frijda, 1986), contributed to predicting more bullying behavior. With heightened levels of anger, bullies can justify their harmful behavior towards another person (Thornberg, Pozzoli, Gini, \& Jungert, 2015).

Although we expected the predictive value of emotional competence to be greater in children with DLD, this was only true for the understanding of one's own basic emotions. Understanding of one's own emotions in this study was represented by a scale from the Emotion Awareness Questionnaire (Rieffe et al., 2008). The items in this scale reflect the capacity to identify the important antecedents in the emotion-evoking situation and how one wants to deal with these in order to arrive at a most optimal outcome (the so-called "action tendency”, Frijda, 1986). This capacity forms the basis for adaptive emotion regulation (Crick \& Dodge, 1994; Gross, 2015). For example, "feeling bad" is only a global negative evaluation 
of a situation that does not offer any insights about how to deal with it. Youngsters who can distinguish between anger and sadness evoked in a peer conflict indicate that they have also identified the harmful elements in the situation that bring different action tendencies (e.g., "I want him to say sorry", aimed at restoring harm, or "I thought he was my friend", aimed at coming on terms with a perceived loss, respectively). This higher level of understanding of one's own emotions is not only related to better mental health (Sendzik, Schäfer, Samson, Naumann, \& Tuschen-Caffier, 2017), but also to more positive peer interactions (Eisenberg et al., 1993; Mavroveli, Petrides, Sangareau, \& Furnham, 2009). The outcomes of our study now confirmed that a better understanding of one's own basic emotions is also predictive of less bullying and less victimization in (pre)adolescents, with and without DLD.

Importantly, this protective factor for victimization was more strongly evident in children with DLD, over and above their communication levels, suggesting that youngsters with DLD benefit differentially from this kind of emotion understanding in their peer relationships. Although only speculative, (pre)adolescents with DLD who have a better understanding of their own emotions can more easily and more strategically express their emotions, or choose not to, because they have a better understanding of the emotion-evoking situation. Future studies could further examine the mechanism underlying this protective factor in youngsters with DLD. In addition, the understanding of more complex emotions in children with DLD should be examined, such as empathy, shame, guilt, and pride. These social and moral emotions are highly dependent on the understanding of others, and may therefore be more difficult to acquire than the understanding of basic emotions when children experience communication problems (Rieffe et al., 2016; Schaffer, 2005).

Notably, only pragmatic language problems were uniquely associated with victimization in addition to emotional competence. This confirms that the social use of language is of more significance than language form and content in peer interactions in 
adolescence (St. Clair et al., 2016). However, these abilities to use language in social communication are often not captured by formal language tests (Norbury et al., 2004). Children are only eligible for extra help when their receptive and/or expressive language abilities fall within the clinical range. Therefore, youngsters who have less pronounced language problems in addition to pragmatic problems may not receive the necessary help.

The social patterns within a classroom affect how youngsters interact (Veenstra et al., 2005). Therefore, the context in which a child is educated may be important to consider (Redmond \& Rice, 1998). Surprisingly, no differences were found in the current study between (pre)adolescents with DLD in mainstream and special education, whereas individuals in special schools are often there due to the severity of their language problems or additional social, emotional, and behavioral difficulties (Knox \& Conti-Ramsden, 2003). However, being among peers who also have DLD, in a setting where teachers are aware of DLD, may make youngsters more patient with each other, which could contribute to better mutual understanding. Because an increasing number of children with DLD are currently being integrated into mainstream schools, it will be important to monitor their emotional and social well-being in these integrated settings.

\section{Limitations}

This study had several limitations. First, some parents of youngsters with DLD did not fill out the questionnaire on communication difficulties, which might not have occurred completely at random. Although we found no differences in children with missing data, the analyses where we accounted for level of communication problems could be less generalizable.

Second, the study is based on self-reports, which may result in bias, as children have to be able to reflect on their own functioning and answer honestly about their perceptions of sensitive topics such as bullying and victimization. In particular in youngsters with DLD, it 
could be questioned whether they are able to understand the language of the questions and reflect their own understandings. However, previous studies which included both self-reports and parent or teacher reports found similar ratings of social, emotional, and behavioral problems in adolescents with DLD (Brownlie et al., 2004; St. Clair et al., 2011). Additionally, the questionnaires we used have proven to be reliable in other groups with communication difficulties and in our study the internal consistencies of the scales were also good. Self-report measures provide an important insight in the experience of youngsters. Parents and teachers often are unaware of these problems, and peer nominations are usually taken in the classroom, whereas bullying can also happen outside the school, in the sport club, or neighborhood. Nevertheless, future studies should include more informants in order to have a clearer picture as to what extent bullying and victimization are occurring within the DLD population.

Third, bullying might involve levels or dimensions that were not detected in the current study. For example, being excluded or ignored in a group is very different and more difficult to detect than deliberate harmful actions by peers. The social form of bullying is a complex construct since it encompasses both overt behaviors, such as making a child do something he or she does not want to do or telling a child he or she cannot play along, and covert behaviors, such as deliberately ignoring a child or spreading nasty rumors about a child (Olweus, 2013). Because bullying becomes more covert during adolescence, detection of these problems can be more difficult (Crick et al., 2002). Future studies should address these different facets of bullying.

\section{Practical implications and conclusion}

Youngsters with DLD are being victimized more often than their peers without DLD. Although the severity of communication problems was associated with victimization, the importance of emotional competence overshadowed their communication problems in (pre)adolescence. High levels of understanding of one's own emotions were protective of 
victimization, especially in children with DLD. Therefore, interventions for (pre)adolescents with DLD should include techniques that can increase understanding of one's own emotions and emotion regulation strategies. This could help youngsters with DLD adapt their reactions to social situations. Moreover, understanding of one's own emotions might help this group to better understand the emotions of others, and interpret social interactions in a more nuanced fashion. Finally, the results underscore that many youngsters bully reactively following victimization, or out of anger. Teachers and parents should be aware of the reactive nature of bullying, and adapt their interventions to interaction patterns between peers.

\section{Acknowledgements}

The authors thank all children who participated in this study, their parents, and schools. We also thank Jennifer Schoerke for correcting our English. This research was supported by the Nuts Ohra Fund (Grant number: 1303-049), the Dutch organization for scientific research (NWO: Grant number: 452-07-004) and Royal Dutch Kentalis. 


\section{References}

American Psychiatric Association. (2013). Diagnostic and statistical manual of mental disorders (5th. Ed.). Arlington, VA: American Psychiatric Publishing.

Andre's-Roqueta, C., Adrian, J. E., Clemente, R. A., \& Villanueva, L. (2016). Social cognition makes an independent contribution to peer relations in children with Specific Language Impairment. Research in developmental disabilities, 49, 277-290.

Bakopoulou, I. \& Dockrell, J. E. (2016). The role of social cognition and prosocial behavior in relation to the socio-emotional competence of primary aged children with specific language impairment. Research in developmental disabilities, 49-50, 354-370.

Bishop, D. V. M., Snowling, M., J., Thompson, P. A., Greenhalgh, T. \& CATALISE-2 consortium (2017). Phase 2 of CATALISE: a multinational and multidisciplinary Delphi consensus study of problems with language development: Terminology. Journal of Child Psychology and Psychiatry, 58(10), 1068-1080.

Botting, N., \& Conti-Ramsden, G. (2008). The role of language, social cognition, and social skill in the functional social outcomes of young adolescents with and without a history of SLI. The British Journal of Developmental Psychology, 26, 281-300.

Brinton, B. Fujiki, M., Hurst, N. Q., Jones, E. R., \& Spackman, M. P. (2015). The Ability of Children With Language Impairment to Dissemble Emotions in Hypothetical Scenarios and Natural Situations. Language, Speech, and Hearing Services in Schools, $46,325-336$.

Brownlie, E. B., Beitchman, J. H.., Escobar, M., Young, A., Atkinson, A., Johnson, C., Wilson, B., \& Douglas, L. (2004). Early language impairment and young adult delinquent and aggressive behavior. Journal of Abnormal Child Psychology, 32(4), 453-467.

Bushman, B. J., \& Anderson, C. A. (2009). Comfortably numb desensitizing effects of 
violent media on helping others. Psychological Science, 20(3), 273-277.

Camodeca, M. \& Goosens, F. A. (2005). Aggression, social cognitions, anger and sadness in bullies and victims. Journal of Child Psychology and Psychiatry, 46(2), 186-197.

Charman, T., Ricketts, J., Dockrell, J. E., Lindsay, G., \& Palikara, O. (2015). Emotional and behavioral problems in children with language impairments and children with autism spectrum disorders. International Journal of Language \& Communication Disorders, 50(1), 84-93.

Cho, S. (2017). Explaining the overlap between bullying perpetration and bullying victimization: assessing the time-ordered and correlative relationships. Children and Youth Services Review, 79, 280-290.

Conti-Ramsden, G., \& Botting, G. (2004). Social difficulties and victimization in children with SLI at 11 years of age. Journal of Speech, Language \& Hearing Research, 47(1), 145-161.

Cook, C. R., Williams, K. R., Guerra, N. G., Kim, T. E., \& Sadek, S. (2010). Predictors of bullying and victimization in childhood and adolescence: A meta-analytic investigation. School Psychology Quarterly, 25(2), 65-83.

Creusere, M., Alt, M., \& Plante, E. (2004). Recognition of vocal and facial cues to affect in language impaired and normally-developing preschoolers. Journal of Communication Disorders, 37, 5-20.

Crick, N., Casas, J., \& Nelson, D. (2002). Toward a More Comprehensive Understanding of Peer Maltreatment: Studies of Relational Victimization. Current Directions in Psychological Science, 11(3), 98-101.

Crick, N. R. \& Dodge, K. A. (1994). A review and reformulation of social-informationprocessing mechanism's in children's social adjustment. Psychological Bulletin, 115: 74-101. 
Dahl, R., \& Gunnar, M. (2009). Heightened stress responsiveness and emotional reactivity during pubertal maturation: Implications for psychopathology. Development and Psychopathology, 21(1), 1-6.

Davies, C., \& Andrés-Roqueta, C., \& Norbury, C. F. (2016). Referring expressions and structural language abilities in children with specific language impairment: A pragmatic tolerance account. Journal of Experimental Child Psychology, 144, 98-113.

Denham, S. A., \& Auerbach, S. (1995). Mother-child dialogue about emotions and preschoolers' emotional competence. Genetic Social and General Psychology Monographs 121, 311-337.

Dockrell, J. E., Lindsay, G., \& Palikara, O. (2011). Explaining the academic achievement at school leaving for pupils with a history of language impairment: Previous academic achievement and literacy skills. Child Language Teaching \& Therapy, 27(2), 223237.

Dunn, J., Brown, J., \& Beardsall, L. (1991). Family Talk About Feeling States and Children's Later Understanding of Others' Emotions. Developmental Psychology, 27(3), 448-455.

Eisenberg, N., Fabes, R. A., Bernzweig, J., Karbon, M., Poulin, R., \& Hanish, L. (1993). The relations of emotionality and regulation to preschoolers' social skills and sociometric status. Child Development, 64(5), 1418-1438.

Ford, J. A., \& Milosky, L. M. (2003). Inferring emotional reactions in social situations: Differences in children with language impairment. Journal of Speech, Language, and Hearing Research, 46, 21-30.

Ford, J. A., \& Milosky, L. M. (2008). Inference Generation During Discourse and Its 
Relation to Social Competence: An Online Investigation of Abilities of Children With and Without Language Impairment. Journal of Speech, Language, and Hearing Research, 51, 367-380.

Frijda, N. (1986). The emotions. Cambridge, Cambridge University Press.

Fujiki, M., Spackman, M. P., Brinton, B., \& Hall, A. (2004). The relationship of language and emotion regulation skills to reticence in children with Specific Language Impairment. Journal of Speech, Language, and Hearing Research, 47(3), 637-646.

Fujiki, M., Spackman, M. P., Brinton, B., \& Illig, T. (2008). Ability of children with language impairment to understand emotion conveyed by prosody in a narrative passage. International Journal of Language and Communication Disorders, 43, 330345.

Geurts, H., Hartman, H., Verté, C., Oosterlaan, S., Roeyers, J., \& Sergeant, H. (2009). Pragmatics fragmented: The factor structure of the Dutch children's communication checklist (CCC). International Journal of Language \& Communication, 44(5), 549574.

Gross, J. J. (2015) Emotion Regulation: Current Status and Future Prospects. Psychological Inquiry, 26 (1), 1-26.

Hart, K. L., Fujiki, M., Brinton, B., \& Hart, C. H. (2004). The relationship between social behavior and severity of language impairment. Journal of Speech, Language \& Hearing Research, 47(3), 647-662.

Im-Bolter, N., \& Cohen, N. J. (2007). Language impairment and psychiatric comorbidities. Pediatric Clinics of North America, 54, 525- 542.

Knox, E. \& Conti-Ramsden, G. (2003). Bullying risks of 11-year-old children with specific language impairment (SLI): does school placement matter? International Journal of Language and Communication Disorders, 38(1), 1-12. 
Knox, E. \& Conti-Ramsden, G. (2007). Bullying in young people with a history of specific language impairment (SLI), Educational \& Child Psychology, 24(4), 130-141.

Kort, W., Schittekatte, M., \& Compaan, E. L. (2008). CELF-4-NL: Clinical Evaluation of Language Fundatmentals-vierde-editie. Amsterdam: Person Assesment and Information B.V.

Kort, W., Schittekatte, M., Dekker, P. H., Verhaeghe, P., Compaan, E. L., Bosmans, M., \& Vermeir, G. (2005). WISC-III NL Wechsler Intelligence Scale for Children. Derde Editie NL. Amsterdam: Harcourt Test Publishers/Nederlands Instituut voor Psychologen.

Kouwenberg, M., Rieffe, C., \& Theunissen, S. C. P. M. (2011). Intrapersonal and interpersonal factors related to depression in DHH youngsters. International Journal of Mental Health \& Deafness, 1, 46-57.

Lahaye, M., Mikolajczak, M., Rieffe, C., Villanueva, L., Van Broeck, N., Bodart, E., \& Luminet, O. (2011). Cross-validation of the Emotion Awareness Questionnaire for children in three populations. Journal of Psychoeducational Assessment, 29, 418-427.

Lindsay, G., \& Dockrell, J. E. (2012). Longitudinal Patterns of Behavioral, Emotional, and Social Difficulties and Self-Concepts in Adolescents With a History of Specific Language Impairment. Language Speech and Hearing Services in Schools, 43(4), 445460.

Longobardi, E., Spataro, P., Frigerio, A., \& Rescorla, L. (2016) Language and social competence in typically developing children and late talkers between 18 and 35 months of age. Early Child Development and Care, 186(3), 436-452.

Mavroveli, S., Petrides, K. V., Sangareau, Y., \& Furnham, A. (2009). Exploring the relationships between trait emotional intelligence and objective socio-emotional outcomes in childhood. British Journal of Educational Psychology, 79(2), 259-272. 
McGrath, L. M., Hutaff-Lee, C., Scott, A., Boada, R., Shriberg, L. D., \& Pennington, B. F. (2008). Children with Comorbid Speech Sound Disorder and Specific Language Impairment are at Increased Risk for Attention-Deficit/Hyperactivity Disorder. Journal of Abnormal Child Psychology, 36, 151-136.

Mok, P., Pickles, P., Durkin, A., \& Conti-Ramsden, K. (2014). Longitudinal trajectories of peer relations in children with specific language impairment. Journal of Child Psychology and Psychiatry, 55(5), 516-527.

Norbury, C. F., Nash, C., Baird, M., \& Bishop, G. (2004). Using a parental checklist to identify diagnostic groups in children with communication impairment: A validation of the Children's Communication Checklist-2. International Journal of Language \& Communication Disorders, 39(3), 345-364.

Norbury, C. F., Vamvakas, G., Gooch, D., Baird, G., Charman, T., Simonoff, E., \& Pickles, A. (2017). Language growth in children with heterogeneous language disorders: a population study. Journal of Child Psychology and Psychiatry, 58(10), 1092-1105.

Olthof, T., Goossens, F. A., Vermande, M. M., Aleva, E.A., \& Van der Meulen, M. (2011). Bullying as strategic behavior: Relations with desired and acquired dominance in the peer group. Journal of School Psychology, 49(3), 339-359.

Olweus, D. (1996). The Revised Olweus Bullying Questionnaire. Research Center for Health Promotion (HEMIL), University of Bergen Bergen, Norway Bergen: Mimeo.

Olweus, D. (2013). School bullying: Development and some important challenges. Annual Review of Clinical Psychology, 9, 751-80.

Podsakoff, P. M., Mackenzie, S. B., Lee, J. \& Podsakoff, N. P. (2003). Common Method Biases in Behavioral Research: A Critical Review of the Literature and Recommended Remedies. Journal of Applied Psychology, 88(5), 879-903. 
Pellegrini, A. D., \& Long, J. D. (2002). A longitudinal study of bullying, dominance, and victimization during the transition from primary school through secondary school. British Journal of Developmental Psychology, 20(2), 259-280.

Redmond, S. M. (2011). Peer Victimization Among Students With Specific Language Impairment, Attention-Deficit/Hyperactivity Disorder, and Typical Development. Language, Speech \& Hearing Services In Schools, 42(4), 520-535.

Redmond, S., \& Rice, S. (1998). The socioemotional behaviors of children with SLI: Social Adaptation or Social Deviance? Journal of Speech, Language \& Hearing Research, $41,688-700$.

Rieffe, C., Dirks, E., Van Vlerken, W. \& Veiga, G. (2016). The empathic mind in children with communication impairments: The case of children who are Deaf or Hard of Hearing (DHH); children with an Autism Spectrum Disorder (ASD); and children with Specific Language Impairments (SLI). In: Slaughter, V. \& De Rosnay, M. (Eds.), Theory of mind development in context. Hove, UK: Psychology Press.

Rieffe, C., Meerum Terwogt, M., \& Bosch, J. D. (2004). Emotional awareness and somatic complaints in children. European Journal of Developmental Psychology, 1, 31-47.

Rieffe, C., Oosterveld, P., Meerum Terwogt, M., Mootz, S., Van Leeuwen, E., \& Stockmann, A.P.A.M. (2011). Emotion regulation and internalizing symptoms in children with Autism Spectrum Disorders. Autism, 15(6), 655-670.

Rieffe, C, Oosterveld, P., Miers, A. C., Meerum Terwogt, M., Ly, V. (2008). Emotion awareness and internalising symptoms in children and adolescents: The Emotion Awareness Questionnaire revised. Personality and Individual Differences, 45, 756761.

Rieffe, C., \& Wiefferink, C. H. (2017). Happy faces, sad faces; Emotion understanding in 
toddlers and preschoolers with language impairments. Research in Developmental Disabilities, 62, 40-49.

Saarni, C. (1999). The Development of Emotional Competence. New York City: The Guilford Press.

Schaffer, H. R. (2005). Social Development. Blackwell Publishing: Malden.

Schwartz, D., Proctor, L. J., \& Chien, D. H. (2001). The aggressive victim of bullying: Emotional and behavioral dysregulation as a pathway to victimization by peers. In: Juvonen, J. \& Graham, S. (Eds.), Peer harassment in school: The plight of the vulnerable and victimized, 147-174. New York: Guilford Press.

Sendzik, L., Schäfer, J. Ö., Samson, A. C., Naumann, E., \& Tuschen-Caffier, B. (2017). Emotional awareness in depressive and anxiety symptoms in youth: A meta-analytic review. Journal of Youth and Adolescence, 46(4), 687-700.

Singer, J. D. \& Willett, J. B. (2003). Applied Longitudinal Data Analysis: Modeling Change and Event Occurrence. New York: Oxford University Press.

Snijders, T. A. B. \& Bosker, R. J. (2012). Multilevel Analysis: An Introduction to Basic and Advanced Multilevel Modeling, second edition. London: Sage Publishers.

Snowling, M. J., Duff, F. J., Nash, H. M. \& Hulme, C. (2016). Language profiles and literacy outcomes of children with resolving, emerging, or persisting language impairments. Journal of Child Psychology and Psychiatry, 57(2), 1360-1369.

Spackman, M. P., Fujiki, M., \& Brinton, B. (2006). Understanding emotions in context: The effects of language impairment on children's ability to infer emotional reactions. International Journal of Language \& Communication Disorders, 41, 173-188.

Spence, S. H., De Young, A., Toon, C., \& Bond, S. (2009). Longitudinal examination of the associations between Emotional Dysregulation, Coping responses to Peer provocation, and victimization in children. Australian Journal of Psychology, 61(3), 145-155. 
Stothard, S. E., Snowling, M. J., Bishop, D. V. M., Chipchase, B. B., \& Kaplan, C. A. (1998). Language Impaired Preschoolers: A Follow-up into Adolescence. Journal of Speech, Language, and Hearing Research, 41(2), 407-418.

St Clair, M. C., Pickles, A., Durkin, K., \& Conti-Ramsden, G. (2011). A Longitudinal study of Behavioral, Emotional and Social difficulties in individuals with a history of Specific Language Impairment (SLI). Journal of Communication Disorders, 44(2), 186-199.

Taylor, L. J., Maybery, L. J., Grayndler, M. T., \& Whitehouse, L. (2015). Evidence for shared deficits in identifying emotions from faces and from voices in autism spectrum disorders and specific language impairment. International Journal of Language \& Communication Disorders, 50(4), 452-466.

Theunissen, S. C. P. M., Rieffe, C., Kouwenberg, M, Soede, W., Briaire, J. J., \& Frijns, J. H. M. (2011). Depression in Hearing-impaired Children. International Journal of Pediatric Otorhinolaryngology, 75(10), 1313-1317

Thornberg, R., Pozzoli, T., Gini, G., \& Jungert, T. (2015). Unique and Interactive Effects of Moral Emotions and Moral Disengagement on Bullying and Defending among School Children. Elementary School Journal, 116(2), 322-337.

Tomblin, J. B., Records, N.L., Buckwalter, P., Zhang, X., Smith, E., \& O'Brien, M. (1997). Prevalence of Specific Language Impairment in kindergarten children. Journal of Speech Language and Hearing Research, 40(6), 1245-60.

Ttofi, M. M., Farrington, D. P., Lösel, F., \& Loeber, R. (2011). Do the Victims of School Bullies tend to become Depressed later in life? A systematic Review and Metaanalysis of Longitudinal studies. Journal of Aggression, Conflict and Peace Research, $3(2), 63-73$.

Ttofi, M, Farrington, D P, Lösel, F (2012). School Bullying as a predictor of Violence later 
in life: A systematic Review and Meta-analysis of Prospective Longitudinal studies. Aggression and violent behavior, 17, 405-418.

Underwood, M. K., Beron, K. J., \& Rosen, L. H. (2009). Continuity and Change in Social and Physical Aggression from Middle Childhood through Early Adolescence. Aggressive Behavior, 35(5), 357-375.

Van Buuren, S. (2012). Flexible Imputation of Missing Data. Boca Raton, FL: Chapman \& Hall/CRC.

Van Daal, J., Verhoeven, L., \& Van Balkom, H. (2007). Behavior problems in children with Language Impairment. Journal of Child Psychology and Psychiatry, 48(11), 1139-1147.

\section{Veenstra, R., Lindenberg, S., Oldehinkel, A. J., De Winter, A. F., Verhulst, F. C., \&} Ormel, J. (2005). Bullying and Victimization in elementary Schools: A comparison of bullies, victims, bully/victims, and uninvolved preadolescents. Developmental Psychology, 41(4), 672-682.

Veiga, G., de Leng, W., Cachucho, R., Ketelaar, L., Kok, J. N., Knobbe, A., Neto, C., \& Rieffe, C. (2017). Social Competence at the Playground: Preschoolers During Recess. Infant and Child Development, 26(1), e1957.

Von Salisch, M. \& Zeman, J. L. (2017). Pathways to Reciprocated Friendships: A CrossLagged Panel Study on Young Adolescents' Anger Regulation towards Friends. Journal of Youth and Adolescence, 2, 10.1007/s10964-017-0683-7.

Wiefferink, C.H. \& Rieffe, C. (2012). De gevolgen van Ernstige Spraak-/Taal Moeilijkheden voor het sociaal-emotioneel functioneren: een overzicht van de literatuur. Logopedie en Fonometrie, 2, 40-44. 
Table 1. Characteristics of participants at Time 1

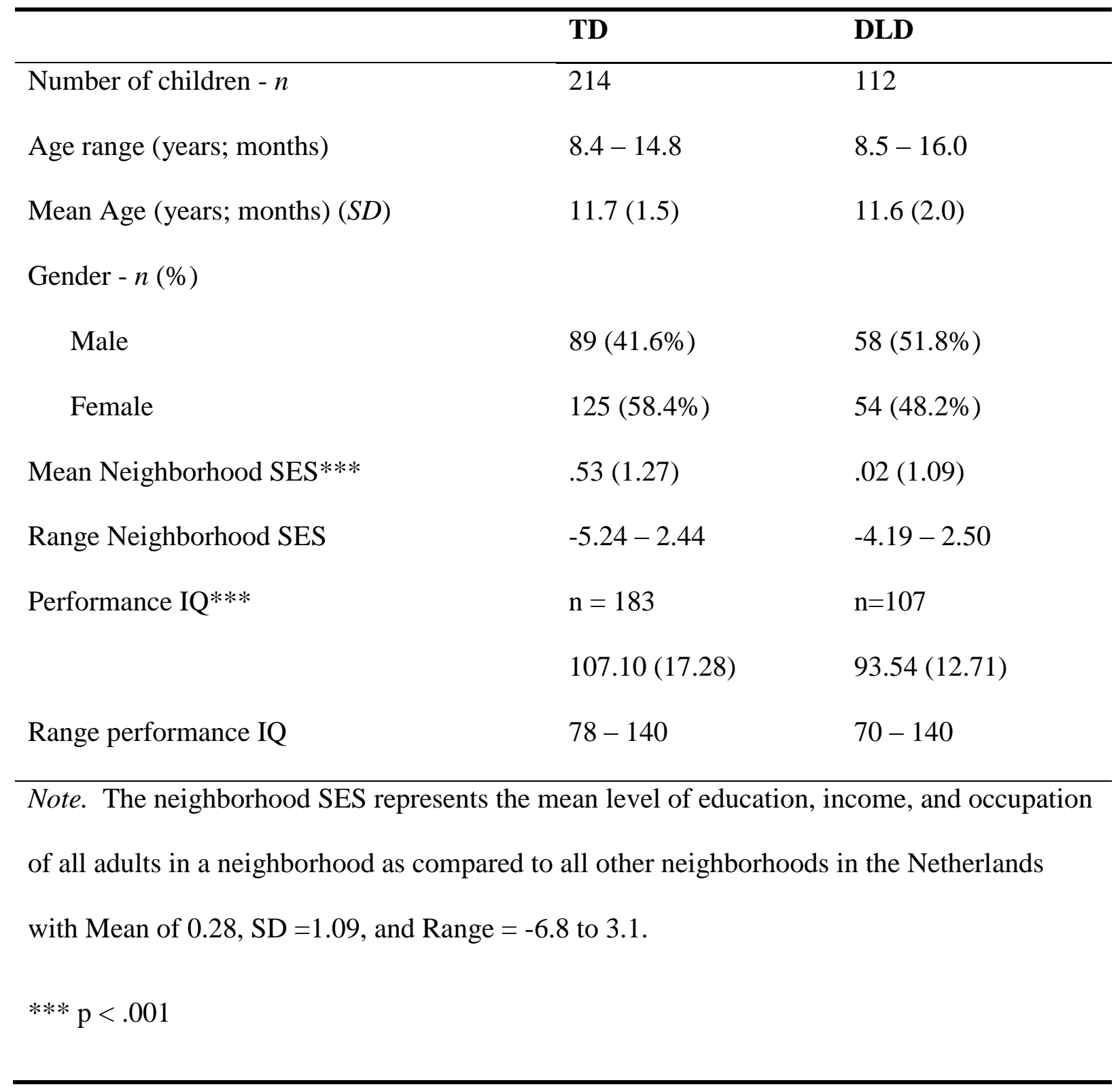


Table 2. Psychometric properties of the questionnaires for children with DLD and typically developing children (TD)

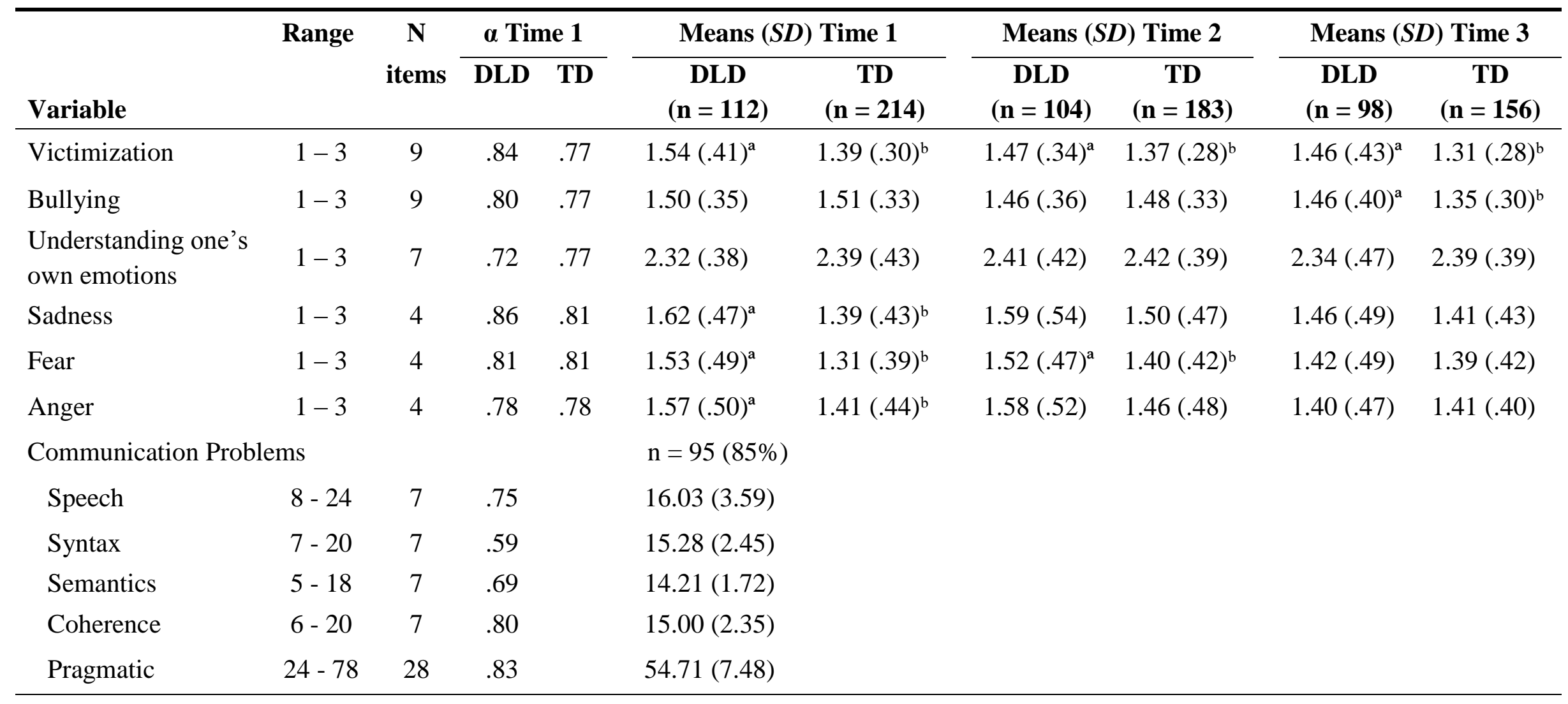

Note: Group differences between children with and without DLD on every time point are indicated by the superscripts for that variable, $p<.05$ 
Table 3. Goodness of fit (AIC) and regression weights with 95\% Confidence Intervals (CI) for Multi- level models explaining the level and development of Victimization, Bullying, and the indices for Emotional Competence.

\begin{tabular}{|c|c|c|c|c|c|c|}
\hline Variables & AIC & Age & Neigh. SES & Gender & Diagnosis & Diagnosis $x$ Age \\
\hline Victimization & 282.4 & $-.05[-.06$ to -.03$]$ & $-.01[-.03$ to .02$]$ & $-.03[-.08$ to .04$]$ & .13 [.07 to .16] & \\
\hline Bullying & 416.5 & $-.02[-.04$ to -.00$]$ & $-.00[-.03$ to .02$]$ & $-.12[-.18$ to -.06$]$ & & \\
\hline Understanding one's & 744.1 & $.03[.01$ to .05$]$ & $.02[-.01$ to .05$]$ & $-.02[-.10$ to .05$]$ & & \\
\hline \multicolumn{7}{|l|}{ own emotions } \\
\hline Anger & 956.2 & $-.00[-.03$ to .03$]$ & $-.01[-.05$ to .02$]$ & $-.09[-.17$ to -.00$]$ & $.08[-.01$ to .17$]$ & $-.07[-.11$ to -.03$]$ \\
\hline Sadness & 996.7 & $.03[-.00$ to .06$]$ & $-.01[-.05$ to .03$]$ & $.09[.01$ to .18$]$ & $.13[.04$ to .22$]$ & $-.08[-.13$ to -.04$]$ \\
\hline Fear & 903.6 & $.01[-.02$ to 0.4$]$ & $-.02[-.05$ to .02$]$ & $.12[.04$ to .20$]$ & $.13[.05$ to .21$]$ & $-.06[-.10$ to -.02$]$ \\
\hline
\end{tabular}


Table 4. Goodness of fit (AIC) and regression weights with 95\% Confidence Intervals (CI) for Multi- level models explaining Victimization and Bullying with the Gender, SES, Diagnosis (DLD = 1), Bullying/Victimization, and Understanding of one's own Emotions (Mean and Change).

\begin{tabular}{|c|c|c|c|}
\hline Predictors & & Victimization & Bullying \\
\hline AIC & & 141.5 & 301.1 \\
\hline Age & & $-.03[-.05$ to -.02$]$ & $.00[-.01$ to .02$]$ \\
\hline Neighborhood SES & & $-.00[-.03$ to .02$]$ & $.00[-.02$ to .03$]$ \\
\hline Gender & & $.01[-.04$ to .06$]$ & $-.12[-.17$ to -.06$]$ \\
\hline Diagnosis & & $.66[.29$ to 1.03$]$ & $-.06[-.12$ to .00$]$ \\
\hline \multirow[t]{2}{*}{ Bullying } & Mean & $.34[.25$ to .44$]$ & - \\
\hline & Change & $.22[.14$ to .29$]$ & - \\
\hline \multirow[t]{2}{*}{ Victimization } & Mean & - & $.37[.27$ to .48$]$ \\
\hline & Change & - & $.29[.20$ to .38$]$ \\
\hline Understanding one's & Mean & $-.15[-.25$ to -.06$]$ & $-.13[-.22$ to -.04$]$ \\
\hline own Emotions & Change & $-.07[-.15$ to .01$]$ & $-.11[-.18$ to -.05$]$ \\
\hline Diagnosis x Understanding & Mean & $-.23[-.38$ to -.07$]$ & \\
\hline
\end{tabular}


Table 5. Goodness of fit (AIC) and regression weights with 95\% Confidence Intervals (CI) for Multi-level models explaining the level of Victimization/Bullying with the control variables, Diagnosis $(\mathrm{DLD}=1)$, Bullying/Victimization, and Anger, Sadness, and Fear (Mean and Change).

\begin{tabular}{|c|c|c|c|}
\hline \multicolumn{2}{|l|}{ Predictors } & Victimization & Bullying \\
\hline \multicolumn{2}{|l|}{ AIC } & 78.0 & 277.4 \\
\hline \multicolumn{2}{|l|}{ Age } & $-.04[-.05$ to -.03$]$ & $.00[-.01$ to .02$]$ \\
\hline \multicolumn{2}{|c|}{ Neighborhood SES } & $-.00[-.02$ to .02$]$ & $.00[-.02$ to .03$]$ \\
\hline \multicolumn{2}{|l|}{ Gender } & $-.03[-.08$ to .02$]$ & $-.10[-.15$ to -.04$]$ \\
\hline \multicolumn{2}{|l|}{ Diagnosis } & $.08[.03$ to .13$]$ & $-.06[-.12$ to -.01$]$ \\
\hline \multirow[t]{2}{*}{ Bullying } & Mean & $.28[.19$ to .38$]$ & - \\
\hline & Change & $.18[.11$ to .25$]$ & - \\
\hline \multirow[t]{2}{*}{ Victimization } & Mean & - & $.31[.20$ to .42$]$ \\
\hline & Change & - & $.26[.17$ to .35$]$ \\
\hline \multirow[t]{2}{*}{ Anger } & Mean & $.05[-.03$ to .13$]$ & $.23[.14$ to .31$]$ \\
\hline & Change & $.04[-.02$ to .10$]$ & $.11[.05$ to .17$]$ \\
\hline \multirow[t]{2}{*}{ Sadness } & Mean & $.19[.10$ to .27$]$ & $-.02[-.11$ to .08$]$ \\
\hline & Change & $.07[.01$ to .13$]$ & $.01[-.05$ to .08$]$ \\
\hline \multirow[t]{2}{*}{ Fear } & Mean & $.15[.06$ to .24$]$ & $.02[-.08$ to .12$]$ \\
\hline & Change & $.09[.03$ to .15$]$ & $.03[-.03$ to .10$]$ \\
\hline
\end{tabular}


Table 6. Goodness of fit (AIC) and regression weights with 95\% Confidence Intervals (CI) for regression models explaining the level of Victimization in youngsters with DLD with the control variables, Bullying, and the addition of Pragmatic Problems, the indices for Emotional Competence and both Pragmatic Problems and Emotional Competence.

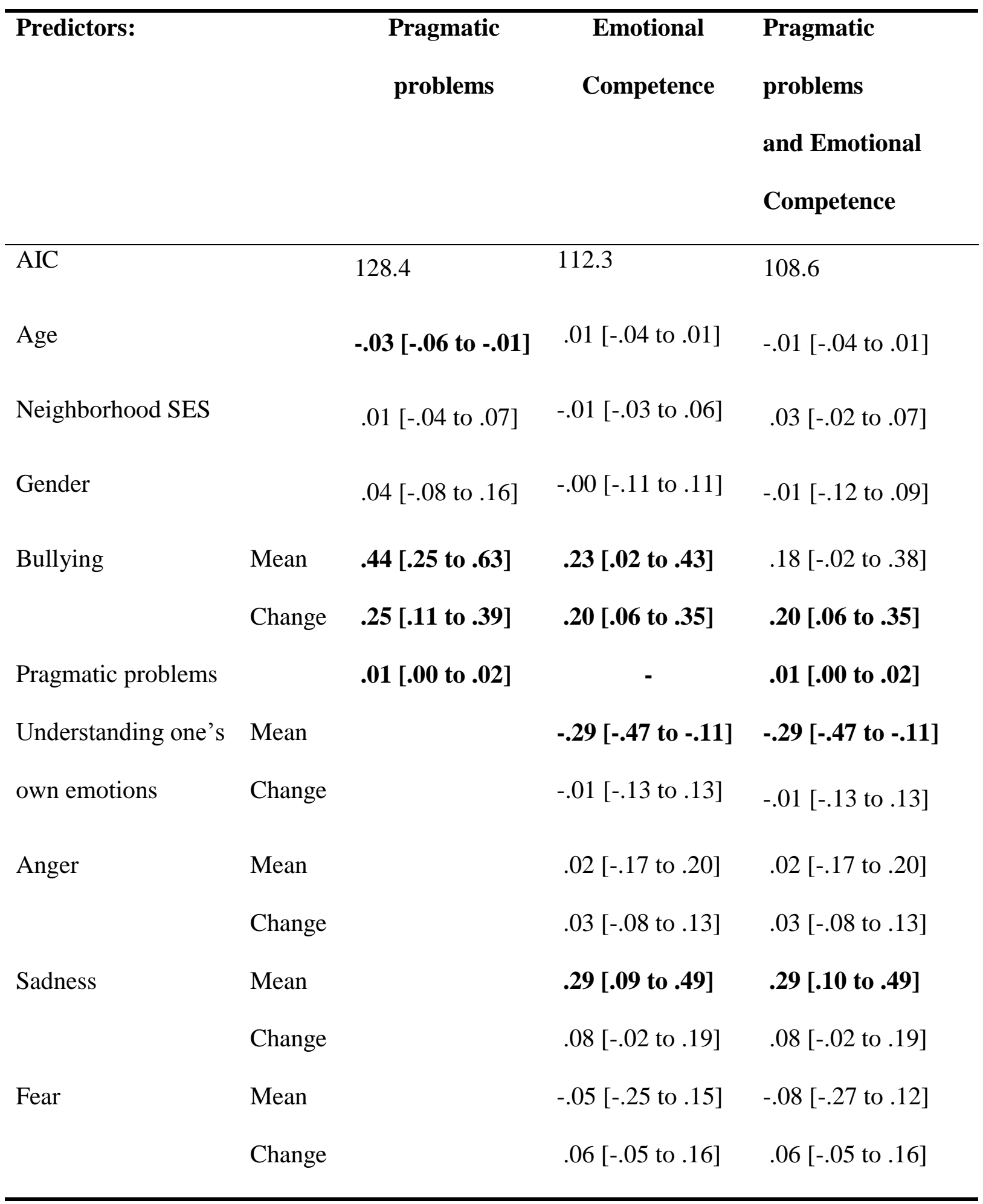



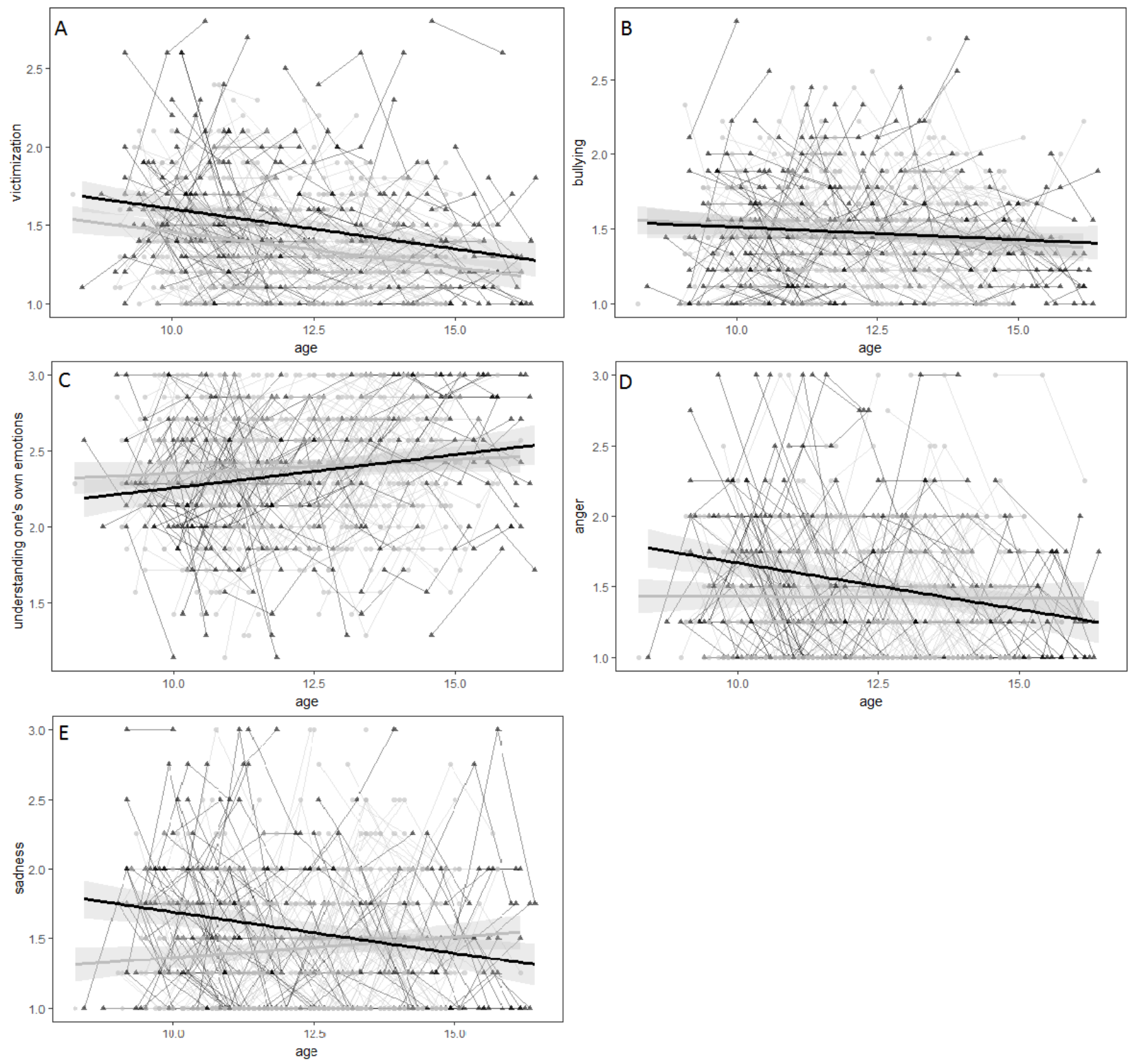

Figure 1. Graphic representation of age at three time points and the level of victimization (1A), bullying (1B), understanding of one's own emotions (1C), anger (1D), sadness (1E), and fear $(1 \mathrm{~F})$. Every measurement is represented by a dot (without DLD), or a square (with DLD). The measurements of one participant are connected with lines. The graphic shows the predicted value of the variables based on the age and diagnosis of the participant. 


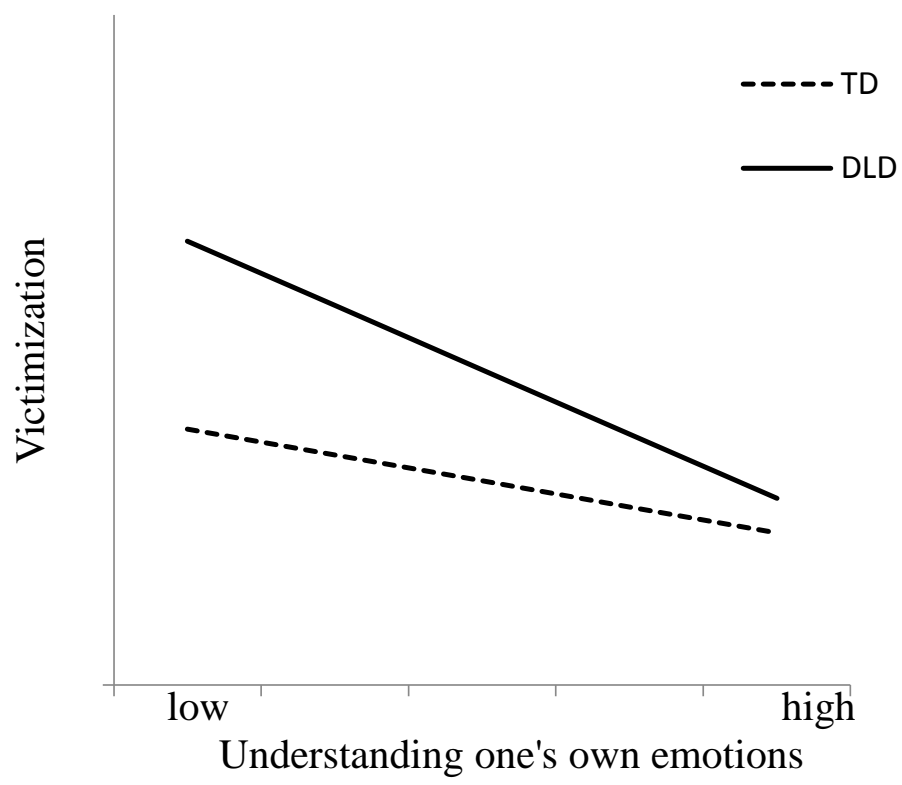

Figure 2. Moderation effect of Group on the longitudinal relation between Mean Understanding of one's own Emotions and Victimization. 
Appendix 1 Goodness of fit (AIC) and regression weights with 95\% Confidence Intervals (CI) for Multi- level models explaining the level and development of Victimization, Bullying, and the indices for Emotional Competence.

\begin{tabular}{|c|c|c|c|c|c|c|c|}
\hline & $\mathbf{M}$ & AIC & Age & Neigh. SES & Gender & Diagnosis & Diagnosis x Age \\
\hline \multirow[t]{3}{*}{ Victimization } & 0 & 332.0 & & & & & \\
\hline & 1 & 295.1 & $-.05[-.06$ to -.03$]$ & $-.02[-.04$ to .01$]$ & $-.04[-.10$ to .02$]$ & & \\
\hline & 2 & 282.4 & $-.05[-.06$ to -.03$]$ & $-.01[-.03$ to .02$]$ & $-.03[-.08$ to .04$]$ & $.13[.07$ to .16$]$ & \\
\hline \multirow[t]{2}{*}{ Bullying } & 0 & 431.6 & & & & & \\
\hline & 1 & 416.5 & $-.02[-.04$ to -.00$]$ & -.00 [-.03 to .02$]$ & $-.12[-.18$ to -.06$]$ & & \\
\hline Understanding one's & 0 & 749.3 & & & & & \\
\hline own emotions & 1 & 744.1 & $.03[.01$ to .05$]$ & $.02[-.01$ to .05$]$ & $-.02[-.10$ to .05$]$ & & \\
\hline \multirow[t]{4}{*}{ Anger } & 0 & 972.4 & & & & & \\
\hline & 1 & 965.4 & $-.03[-.05$ to -.01$]$ & $-.02[-.05$ to .02$]$ & $-.08[-.17$ to .00$]$ & & \\
\hline & 2 & 964.0 & $-.03[-.05$ to -.01$]$ & $-.01[-.05$ to .03$]$ & $-.08[-.16$ to .01$]$ & $.08[-.01$ to .17$]$ & \\
\hline & 3 & 956.2 & $-.00[-.03$ to .03$]$ & $-.01[-.05$ to .02$]$ & $-.09[-.17$ to -.00$]$ & $.08[-.01$ to .17$]$ & $-.07[-.11$ to -.03$]$ \\
\hline \multirow[t]{2}{*}{ Sadness } & 0 & 1017.3 & & & & & \\
\hline & 1 & 1016.5 & $-.01[-.03$ to .01$]$ & $-.02[-.05$ to .02$]$ & $.09[.01$ to .18$]$ & & \\
\hline
\end{tabular}




\begin{tabular}{|c|c|c|c|c|c|c|c|}
\hline & 2 & 1009.7 & $-.01[-.03$ to .01$]$ & $-.01[-.04$ to .03$]$ & $.11[.02$ to .19$]$ & $.14[.05$ to .23$]$ & \\
\hline & 3 & 996.7 & .03 [ -.00 to .06] & $-.01[-.05$ to .03$]$ & $.09[.01$ to .18$]$ & $.13[.04$ to .22$]$ & $-.08[-.13$ to -.04$]$ \\
\hline \multirow[t]{4}{*}{ Fear } & 0 & 927.2 & & & & & \\
\hline & 1 & 918.6 & $-.02[-.04$ to .00$]$ & $-.03[-.06$ to .01$]$ & .12 [.04 to .19] & & \\
\hline & 2 & 909.9 & $-.02[-.04$ to .00$]$ & $-.01[-.05$ to .02$]$ & $.13[.05$ to .21$]$ & $.14[.06$ to .22$]$ & \\
\hline & 3 & 903.6 & $.01[-.02$ to .04$]$ & $-.02[-.05$ to .02$]$ & $.12[.04$ to .20$]$ & $.13[.05$ to .21$]$ & $-.06[-.10$ to -.02$]$ \\
\hline
\end{tabular}


Appendix 2 Goodness of fit (AIC) and regression weights with 95\% Confidence Intervals (CI) for Multi- level models explaining Victimization and Bullying with Age, Neighborhood SES, Gender (Girls = 1), Diagnosis (DLD = 1) and Bullying/Victimization in Model 1, Understanding one's own emotions in Model 2, and the interaction of Diagnosis x Understanding one's own emotions in Model 3.

\begin{tabular}{|c|c|c|c|c|c|c|}
\hline & & Victimization & & & Bullying & \\
\hline & & Model 1 & Model 2 & Model 3 & Model 1 & Model 2 \\
\hline AIC & & 177.4 & 145.9 & 141.5 & 315.9 & 301.1 \\
\hline Age & & $-.04[-.06$ to -.03$]$ & $-.04[-.05$ to -.02$]$ & $-.03[-.05$ to -.02$]$ & $.00[-.02$ to .02$]$ & $.00[-.01$ to .02$]$ \\
\hline Neighborhood SES & & $-.00[-.03$ to .02$]$ & $-.00[-.03$ to .02$]$ & $-.00[-.03$ to .02$]$ & $.00[-.02$ to .03$]$ & $.00[-.02$ to .03$]$ \\
\hline Gender & & $.03[-.03$ to .08$]$ & $.01[-.04$ to .07$]$ & $.01[-.04$ to .06$]$ & $-.11[-.17$ to -.06$]$ & $-.12[-.17$ to -.06$]$ \\
\hline Diagnosis & & $.13[.07$ to .19$]$ & $.12[.07$ to .18$]$ & $.66[.29$ to 1.03$]$ & $-.06[-.12$ to .00$]$ & $-.06[-.12$ to .00$]$ \\
\hline \multirow[t]{2}{*}{ Bullying } & Mean & $.44[.35$ to .54$]$ & $.35[.26$ to .45$]$ & $.34[.25$ to .44$]$ & - & - \\
\hline & Change & $.22[.15$ to .30$]$ & .21 [.14 to .29$]$ & .22 [.14 to .29$]$ & - & - \\
\hline \multirow[t]{2}{*}{ Victimization } & Mean & & - & - & $.44[.34$ to .53$]$ & $.37[.27$ to .48$]$ \\
\hline & Change & & - & - & $.30[.22$ to .40$]$ & $.29[.20$ to .38$]$ \\
\hline Understanding one's & Mean & & $-.23[-.31$ to -.15$]$ & $-.15[-.25$ to -.06$]$ & & $-.13[-.22$ to -.04$]$ \\
\hline
\end{tabular}


own emotions

Diagnosis x Underst. Mean

$-.23[-.38$ to -.07$]$

one's own emotions

$.01[-.11$ to .13$]$

Note $:$ AIC $=$ Akaike information criterion 